\title{
Street-Vended Local Foods Transformation: Case of Hausa Koko, Waakye and Ga Kenkey in Urban Ghana
}

\author{
Joyce Afua Sarpong Haleegoah'1, Guido Ruivenkamp², George Essegbey³, \\ Godfred Frempong ${ }^{3}$, Joost Jongerden ${ }^{2}$ \\ ${ }^{1}$ CSIR-Crops Research Institute, Kumasi, Ghana \\ ${ }^{2}$ Social Science Group (RSO), Wageningen University, Wageningen, The Netherlands \\ ${ }^{3}$ CSIR-Science and Technology Policy Research Institute (STEPRI), Accra, Ghana \\ Email: haleegoahj@yahoo.co.uk,guido.ruivenkamp@wur.nl,george_essegbey@yahoo.co.uk, \\ goddie58@yahoo.com,joost.jongerden@wur.nl
}

Received 14 December 2015; accepted 7 March 2016; published 10 March 2016

Copyright (C) 2016 by authors and Scientific Research Publishing Inc.

This work is licensed under the Creative Commons Attribution International License (CC BY). http://creativecommons.org/licenses/by/4.0/

c) (†) Open Access

\section{Abstract}

People in Ghana accept various dishes as national foods that originally, were consumed in particular regions and among particular ethnic groups. These foods form part of the national culture and are developed through several processes. National food cultures are developed through a simultaneous process of ethnic specialization and the advancement of national cuisines, which bring into focus the local as well as the national aspects of foods. The approach to this study was case study methodology with different data collecting tools in three cities: Accra, Kumasi and Tamale in Ghana. We developed literature on transformation of food-cultures and showed how the process of migration of people produced cuisines in contemporary Ghana and transformed ethnic dishes into national ones. Through the memories and narratives of female vendors' knowledge on the preparation and vending skills, these cuisines were transferred to other people. The results showed how local foods continued to exist, how some aspects of local foods had changed, and the underlying cultural migration and the producing food vendors and consumers that influenced food transformation. We concluded that several factors mediated this dynamism in Ghanaian foods.

\section{Keywords}

Street Vended Local Foods, Food Transformation, Hausa Koko, Waakye, Ga Kenkye 


\section{Introduction}

In Ghana, people accept dishes associated with particular ethnic groups as national foods. National foods are those that people of different ethnic backgrounds and nationalities accept and are produced and consumed nationwide. These foods are sold as street foods and are referred to as street vended local foods (SVLFs). SVLFs are defined as specific local foods associated with some particular ethnic groups in Ghana, which are prepared and sold as ready-to eat meals in the streets (Haleegoah et al., 2015). However, the processes these ethnic specific foods go through into being accepted nationwide are under studied. This paper seeks to study this by analyzing the factors underlying these processes in three selected local foods. The paper posits that these processes lead to transformations but the local dishes maintain their local identities despite their nationwide acceptance.

Studies show a close relationship with the development of food cultures or cuisines and the development of national identities (Appadurai, 1988, 2008; Cusack, 2000; Palmer, 1998; Cook and Crang, 1996; Pilcher, 1996). Several factors go into developing this relationship. Colonial encounters and recipe books, for example, contribute to nationalizing foods (Cusack, 2000). Thus, foods that people perceive as indigenous or local have already had some pre-colonial and colonial interactions. Currently these indigenous or local foods have developed through several processes with global influences; they transform, change or modify and are continually changing (Osseo-Asare, 2005) but literature on such changes is limited in developing countries.

Transformation of foods, the paper defines as changes or modifications that have occurred in the ingredients used for food preparation, in processes of preparation and food packaging as well as serving methods. There are underlying factors that mediate local food transformation, translating them from ethnic into national identities. The paper uses three SVLFs, namely Hausa koko, waakye and Ga kenkey as example because of their nationwide production and consumption as street food. The research examines transformations and their underlying factors in these SVLFs. A brief description of these foods in the next paragraph provides a background to the original nature of these foods and the reason for their selection as cases for the study.

Hausa koko (koko) is porridge made from fermented millet (Pennisetum glaucum) or sorghum (Sorghum bicolor) mixed with spices such as pepper (Capsicum annuum); ginger (zingiber officinale); black pepper (piper nigrum) and xylopia (xylopia aethiopica). It is served hot with “koose” (fried cowpea-Vigna unguiculata-paste) or "maasa" (fried millet, sorghum or corn paste) as accompaniments. Waakye (Hausa word for cowpea) is rice and cowpea (red or brown) cooked together with some kawu (Saltpeter-potassium nitrate). It is served with hot pepper and tomato sauce; black paper sauce and fish, meat or cow skin accompanied with gari (cassava grits) and "taalia" locally prepared spaghetti. Ga kenkey (kenkey) is fermented corn dough, which is steamed and wrapped in dried cornhusks. Amoa Awua et al. (2007) provided a detailed flow chart for the production of kenkey. It is served with hot pepper and tomato sauce or black paper sauce and fish.

Geographically, koko and waakye originate from northern Ghana where millet, sorghum, rice and cowpeas are mostly grown. These dishes are associated with the Hausa speaking people who settled in Northern Ghana. Kenkey on the other hand, originates from coastal Ghana where maize is grown. Kenkey is associated with the Ga people who had early colonial encounter with maize. The basis for the choice of these dishes is that though, they are associated with Hausa and Ga ethnic groups, currently, most Ghanaians recognized them as national foods served as street foods and in sit-down restaurants in urban areas.

However, we believe that in the processes of gaining national identities, these foods undergo some transformations. Cuisines are transformed over time and space; they are dynamic and constantly changing (Osseo-Asare, 2005). Appadurai $(2008,1988)$ referred to a simultaneous process of regional and ethnic specialization, on one hand, and the development of general crosscutting national cuisines, on the other when he looked at cooked books in India. Palmer (1998) showed that the choice and pattern of what is eaten connote people's culture and identity and that national identity is related to three key areas in everyday life namely, body, food and landscapes. She argued that these represent a nation just like other recognized symbols as currency, customs, anthems and national ceremonies/festivals.

Couderc (1995) showed the significant factor food had made towards the building of the French national identity. Furthermore, Pilcher (1996) described the complex nature of culinary history in Mexican national identity from the influences of cuisine of diverse origins. Ohna et al. (2012), showed how food consumption conveyed the identities, status and social distinction of people within communities in Africa. From this literature, we can somehow deduce that indeed cuisines provide a form of identity for people as well as for nations.

Consequently, it is not easy to distinguish between what local foods and global foods are (Quaye et al., 2010; 
Ruivenkamp and Jongerden, 2005; Yeung, 1998; Eade, 1997). They influence one another and are transformed or modified. The process of transformation or modification in foods is described in relation to Chinese cuisines (Huat, 2001). Within non-Chinese cultures, people especially food vendors and chefs combined or substitute different ingredients and presentation styles but these foods maintained their unique identities as Chinese (Huat, 2001). Again, Smart (2003) discussed how a Chinese immigrant had to learn how to cook the Canadian style Chinese food (deep-fried topped with lots of sweet thick sauce). Though this food is Chinese, it has been adapted into the Canadian food culture with some additional ingredients and presentation styles.

From these, we infer that several factors go into the development of national food cultures. However, there is limited literature on food transformation in Africa and Ghana in particular. Contributing to this literature on Ghana, the research was carried to document some of the processes through which three specific SVLFs have developed as national foods in urban Ghana. It investigates what factors had influenced the national acceptance of specific ethnic-based foods. In addition, it studied what changes had occurred in these foods over time by further examining modifications in the ingredients used for their preparations, methods of cooking, packaging, and serving accompaniments. Finally, it examines how food vendors and consumers' cultural background and mediations have transformed these foods from ethnic or sectional foods into national ones.

\section{Methodology}

We employed the case study methodology with a mixture of qualitative and quantitative tools for data collection to understand food transformation and the underlying cultural factors influencing transformation in the three local dishes_-koko and waakye and kenkey_in Ghana. Key informants-, informal individual-interviews, focus group discussions and observations as well as consumer questionnaire survey were used to collect primary data from food vendors and consumers. Table 1 provides the gender breakdown of vendors and consumers and the different data collecting tools used. The interviews and survey covered 724 people comprising 75 food vendors and 649 consumers with 58\% men and 42\% women. Secondary information from literature was used together with information from key informants for a historical overview of the three studied foods.

Locations of study were Tamale, Accra and Kumasi, three cities where streets foods are very popular. Tamale served as the geographical origin of koko and waakye where the Hausa ethnic group associated with the foods is mostly located. The environments are also suitable for the growing of crops used for their preparation. Accra is the origin of kenkey where the Ga ethnic group associated with the food is located and maize used for its preparation is grown. Kumasi is a neutral ground where none of these foods originated and the food ingredients are available for their preparation. The choice of these locations was to determine whether the ethnic origins might influence the ingredients used, method of cooking, packaging and serving of these foods. Two Sub-metros within these locations were selected, namely: Tamale Central and Tamale South for Tamale, Ablekuma Central and Okai Koi North for Accra and Oforikrom and Bantama for Kumasi.

The researcher visited major streets in these Sub-metros where vendors sold foods and selected willing vendors and consumers for the study. Data collection was between November 2010 and December 2011. Information collected included the respondents' knowledge of changes in ingredients used, preparation, packaging and serving methods, reasons for changes, and how far specific ethnic-based foods were accepted as national Ghanaian foods. Also covered were the effect of urbanization; migration of people and their food cultures; and personal accounts of food vendors as factors of changes in these studied foods.

Table 1. Actors interviewed and tools used for data collection.

\begin{tabular}{|c|c|c|c|c|c|}
\hline \multirow{3}{*}{ Tools Used } & \multicolumn{5}{|c|}{ Actors Interviewed } \\
\hline & \multicolumn{2}{|c|}{ Food Vendors } & \multicolumn{2}{|c|}{ Consumers } & \multirow[t]{2}{*}{ Totals } \\
\hline & Males & Females & Males & Females & \\
\hline $\begin{array}{l}\text { Informal individual interviews/Key } \\
\text { informants/Observation }\end{array}$ & 2 & 52 & 12 & 6 & 72 \\
\hline Focus Group Discussions & 6 & 15 & - & - & 21 \\
\hline Consumer Survey & - & - & 403 & 228 & 631 \\
\hline Totals & 8 & 67 & 415 & 234 & 724 \\
\hline
\end{tabular}


Reflective analysis began with data collection and clarification to confirm information gathered. Transcribed interview data were analyzed using content analysis while survey data were analyzed with statistical package for social sciences (SPSS) version 16, using descriptive analysis. This paper uses survey results only for the demographic characteristics of consumers.

\section{Results}

\subsection{Local Foods History}

Cereals used in making koko, waakye and kenkey were millet, sorghum, rice and maize respectively. Additional ingredients were cowpea, pepper, tomato and onion. Others included okra, lettuce, cabbage, and carrot as well as melon seeds prepared into sauces and salads to accompany the cereals. Secondary information showed that millet, sorghum and Oryza glaberrima (local rice) were indigenous to West Africa (Osseo-Asare, 2005). However, Oryza sativa and maize were introduced through colonization (Atlin, 2011; Osseo-Asare, 2005). Cowpea had conflicting origin from Africa, Asia and South America (Osseo-Asare, 2005; Coetzee, 1995; Tindall, 1983; Summerfield et al., 1974; Johnson, 1970).

The history of local dishes connects with the agricultural production that prevailed in the areas where they originated. For instance, northern Ghana agricultural ecologies favored the cultivation of millet and sorghum. However, all ecologies in Ghana favor the cultivation of maize, rice and cowpea. Key informants indicated that the studied foods had no known history; their elders claimed their grandparents made and ate these foods.

From interviews and observations, Ga kenkey was originally very hard and heavy in order to last long after eating among the Ga speaking people of coastal Ghana. Anglers ate it when they went into sea for fishing so they would not go hungry quickly. Its local name connotes this hardness. From linguistic point of view, the local name "Ga koumi" or "koumi", is the shortened form of "kou ni omi" which literally means bite and swallow. This depicted something hard confirming that the food was prepared hard so that it could be bitten and swallowed. Vendors indicated that currently, they prepare Ga kenkey soft, which modern consumers demanded.

\subsection{Transformations in Local Foods}

Local foods change and are changing with several interactions but people continue to consider them local. For instance, most respondents perceived the three studied foods as local because they are grown, prepared traditionally and consumed in Ghana. Therefore, some respondents, for example, did not consider cabbage as a 'worldwide food product', even though it is an exotic crop grown in Ghana. Instead as an exotic crop, cabbage has integrated well into the local food system as a locally grown food crop, as ingredient in our local dishes and as part of the national food culture.

Original ingredients used for the preparation of koko had not changed. However, some vendors have added corn dough to supplement the millet/sorghum used. This is because of the high cost of millet and sorghum during the lean seasons. Most of the sampled vendors indicated their knowledge of this adaptation but mentioned they did not use it. Spices had not changed; the quantities used however, depended on vendors' skills in food preparation and consumers' preference leading to some modifications in the food.

The original method of preparation had not changed. However, when corn dough is to be added, they mix corn dough with water and cook for some time before the millet or sorghum mixture was added bring some variations in the preparation methods. An observed modification was the means of boiling water. The use of firewood to boil water was less common than charcoal, electric heaters and gas stoves because the last two were more efficient and economic. This modification was common in Accra and Kumasi because of the shortage of firewood, high cost, inconvenience and the health hazard from smoke. In Tamale, however, most vendors continued to use firewood, as it was most available all-year-round though some indicated an increased cost during rainy seasons, when supply become difficult.

Changed packaging that is the use of transparent polythene film bags (known as rubber), plastic bowls and Styrofoam cups instead of calabashes or enamel bowls and cups are the new additions. Some consumers preferred calabashes but most vendors had stopped using them. They are difficult to clean for continual use and become moldy during rainy seasons where there is limited sunshine for drying. Again, environmental health officers (EHOs), the government's regulatory body for the activities of food vendors, encouraged the single use of polythene bags. Where vendors used plastic bowls to serve for immediate consumption, EHOs encouraged the 
use of clean running water for washing. Large quantities of koko were previously served from earthenware pots but now from big aluminum containers covered with several polythene sheets or in plastic warmers to keep the porridge hot and safe. There were current global influences on the local food systems. For instance, manufacturers packaged koko flour in polythene bags and boxes for easy cooking at home.

Serving, defined as food accompaniments, has also changed with additional accompaniments to improve their nutrition and calories. Some vendors indicated these changes were not of recent introductions. They had been with them for more than twenty years and so they did not see them as change. Koko still maintained koose (fried bean cake), maasa (fried millet, sorghum or corn cake) and groundnuts as accompaniments. Other (more recent) accompaniments were bread, doughnuts, "kulikuli” (prepared from the residue of extracted groundnut oil), and koose enriched with eggs or vegetables as well as milk.

Some ingredients of waakye had changed by substitution and addition. White cowpea replaced brown or red cowpea. Imported white rice was used in addition to the local white or brown rice. Most vendors in Accra used white rice (imported or local) and white or cream colored cowpea to avoid the labor of cleaning brown rice and red or brown cowpea. Vendors who were used to cooking with brown rice continued to use it. Vendors did not use red and brown cowpea everywhere because apart from the time spent cleaning the materials and the long cooking hours involved, they had complaints from consumers about indigestion. In Tamale, vendors used locally grown white rice because the brown type was not always available. The initial understanding was that brown rice was from Northern Ghana but one key informant indicated that traders brought it from the Brong Ahafo region. People in the North grew white rice and white cowpea so they were always available for use.

Most vendors used baking soda (sodium bicarbonate) instead of "kawu” (Saltpeter or potassium nitrate) and dried millet stalks as a coloring agent to maintain the foods original appearance because of the change to white cowpea. In all locations, vendors used dried millet stalks but the preparation processes were different. In Tamale, they were soaked overnight and the water used to boil cowpea before adding rice. In Accra, vendors cooked dried millet stalks together with cowpea and removed them when they obtained the required color of the cooking water before adding rice. In Kumasi, however, the two practices existed depending on the processor but most vendors who used brown rice did not add any dried millet stalks at all.

Most vendors prepared waakye on charcoal pot; one in Tamale regularly used firewood but used charcoal pot during the rainy season. One respondent used gas stove for the preparation of waakye in Accra but no one in Tamale and Kumasi.

Environmental health regulators advised against the use of leaves (Calathea lutea) for the wrapping of food due to the unhygienic way vendors used them. The other reasons were that leaves dried up easily and inconvenienced some to consumers-Oil from food could spill onto people's cloths and children could spill hot food in leaves to the ground. Vendors used polythene bags and Styrofoam made into bowls for packaging. Consumers ate at the sale point from plastic plates and bowls. For large quantity packaging, vendors used aluminum pans covered with lots of polythene sheets or plastic warmers. They packed fish, chicken, salads, and other accompaniments in glass or netted cases.

Additional accompaniments were vegetable salad, avocado pear and commercial spaghetti and macaroni, which replaced the laborious and time-consuming manner of preparing local spaghetti. Some vendors did not see these as changes because they had used them over twenty years. They were however, now imitating the way vendors of fried rice displayed their salads, chicken, and other accompaniments in glass cases. Most vendors' points of sales were fabricated metal and glass stands or tables with raised netted covers to protect food from attracting flies and dusts instead of ordinary tables without nets. Vendors provided tables covered with clean plastic sheets and chairs for consumers who ate at the sale points.

Some vendors had not changed the ingredients for the preparation of kenkey. However, others added cassava dough to the partially cooked corn dough before adding the fresh dough to make it soft without any change in the preparation process. This is a complete change from what kenkey used to be, that is, a move from hard to soft currently. We observed a different version of kenkey preparation in Kumasi where a vendor did not add fresh raw corn dough to the semi-cooked corn and cassava dough. After cooling the almost cooked dough, she wrapped the serving sized balls in cornhusk and steamed them for a short time. The vendor with her brother, also a kenkey vendor, did not see this as a change because they had learned the method when they started with their deceased mother thirty years before. The vendors mentioned that this process, apart from meeting consumers demand for softness, shortened the long and laborious traditional method. Further probing into this from a vendor who was a Ga, noted that a typical Ga would not add cassava dough to her kenkey but knew how to mix 
well the raw and semi cooked corn dough to make it soft for consumers.

Changes in packaging of kenkey and the reasons for change were similar to that of wakye mentioned earlier. Some food industries packaged fermented corn dough flour in polythene bags and boxes for convenient use at home.

Consumers and vendors indicated to the researcher that serving kenkey with additional accompaniments were not of recent introductions as in the case of waakye. Key informants confirmed that vendors had served kenkey with hot pepper sauce, chopped onion, tomato, and fresh fried or tinned fish as well as black pepper sauce (sheto) for more than twenty years. Currently, they add sauces such as cowpea, okra, aleefu (Amarantus Spp; common in Tamale) and light soup.

Most kenkey vendors sold their foods from fabricated metal and glass stands or tables with raised netted cover instead of ordinary tables attracting flies and dust. Where they had no such stands, they placed fish and sauces in netted sieves or glass cages instead of on bear trays. Sale points had cleaned plastic sheet covered tables and chairs for consumers.

\subsection{Accepting Ethnic-Based Local Foods Nationally}

National foods are foods that are generally accepted and recognized by national institutions and governing structures of a nation and provides the national food culture and identity. Nations are identified with certain foods and cuisines and several mediums and actors promoted the production and consumption of these foods nationwide. For instances, the most recent cookbooks written by Ghanaians abroad included these studied foods in their recipes as part of the Ghanaian cuisine (Agbozo, 2007; Kudonoo, 2007; Boahene, 2003). These recently released cookbooks had come as a realization of the importance of documenting these recipes, once based on oral tradition of the nation (Osseo-Asare, 2008). Again, listed at the national websites of tourism and other official sites of Ghanaian foods are these three studied foods as among Ghana's favorite dishes.

(http://www.touringghana.com/dining.asp\#top; http://www.ghananation.com/tourism/Local-Favorite-Dishes-you-must-definitely-try.asp).

Furthermore, a critical analysis of some private and the national television stations showed that they all had at least once in a week, a program that promoted local dishes. Observations indicated that some television programmes promoted these local foods for national acceptance. Very often, the actual intention would be to promote the products of the sponsoring companies. "Onga food tour" for instance, advertised their seasoning products (made from local ingredients) used for the preparation of these local foods and "Edziban" advertised Royco (made from local ingredients) spice at local food spots all over the country.

Apart from these, the study results show that local foods are brought into the national sphere through the memory narratives and actions of food vendors and migration of consumers of diverse ethnic groups to different places in the country. Food vendors translate their skills to their descendants especially their daughters and other women and provide local foods in urban places on one hand. On the other hand, consumers with their own or acquired taste for these local dishes demands them in these urban places. Thus, with this demand and supply, cultural migration of food vendors and consumers due to urbanization drive the national acceptance of ethnicbased foods.

\subsubsection{Food Vendors and Consumers Ethnic Identities}

As people moved to places, they moved along with their culture, including foods, their skills and tastes. Vendors of the three studied foods had all migrated in one way or another. In all locations, vendors of koko and waakye interviewed and observed were Hausa speaking people and mainly from one of the Northern ethnic groups (Table 2), though others have learnt to prepare such foods. Actually one waakye vendor had her routes from Burkina Faso. One koko vendor was from Kejebi in the Volta region and another from Offinso in the Ashanti. These foods had spread with the migration and spread of Hausa people throughout the country.

All kenkey vendors were of different ethnic groups (Table 2). This is because corn is grown in all agroecologies in Ghana. People tend to use corn for a range of dishes including the several types of kenkey. Kenkey stands out with a common principle of preparation, though with diverse versions depending on the local natural resources available at the different parts of the country. These versions could also be attributed to the experimental nature of food where people try-out with foods and come out with desirable designs and types. They maintain their identity as kenkey despite the different versions. 
Data from the consumer survey also showed that consumers of the three studied foods were of different ethnic backgrounds (Table 3) and would look for their traditional foods everywhere they are. Someone (from Greater Accra region) who knew how to prepare kenkey would prepare and sell to those who wanted but had no time to cook it at home in Kumasi for instance. Once it was prepared and sold, many people from different ethnic groups would experiment with it. Once people acquired the taste, whether from the Greater Accra region or not, the food vendor would be in business with many customers.

The helpers or assistants, wherever they are from, could learn on the job and begin their own food-vending businesses when ready with the little amount of capital required. This process goes on and on with all other SVLFs. This means that consumers' demand for these local foods in urban areas whether from same or other ethnicity spread the consumption of these foods.

During the study, people were asked why they accepted some local foods of some ethnic groups. Their responses pointed to urbanization as the main reason. This was because people, who moved from place to place, would want to enjoy their local dishes but also acquired different food tastes of their hosts. Again, the ease of learning on the trade, as a means of livelihood for vendors in cities and the availability of ingredients everywhere in the country through trading spread the production and consumption of local foods.

People of different ethnic groups, not only Ga people for instance, could learn to prepare and could develop the taste for kenkey. Whether with the original taste and preparation method or not, it was still perceived as Ga kenkey. In the migration process, women vendors are crucial in maintaining these national food cultural identities.

Table 2. Ethnic background of food venders.

\begin{tabular}{|c|c|c|c|}
\hline \multirow{2}{*}{ Ethnic Background } & \multicolumn{3}{|c|}{ SVLFs } \\
\hline & Hausa koko & Waakye & Ga Kenkey \\
\hline Northern Ghana* & 9 & 18 & 7 \\
\hline Ashanti & 1 & - & 3 \\
\hline Ewe & 1 & - & 2 \\
\hline Ga & & & 3 \\
\hline Fanti & & & 5 \\
\hline Sefwi & & & 1 \\
\hline Akyem & & & 1 \\
\hline Krobo & & & 1 \\
\hline Others & 1 (Nigeria, Hausa) & & 1 (Moshe of Burkina Faso) \\
\hline
\end{tabular}

"Northern Ghana ethnic groups comprises ethnic groups from Northern, Upper East and Upper West Regions of Ghana.

Table 3. Ethnic background of consumers.

\begin{tabular}{ccc}
\hline Ethnic Background & Number & $\%$ \\
\hline Akan & 290 & 46.0 \\
Ga/Ga Adangbe & 46 & 7.3 \\
Ewe & 60 & 9.5 \\
Northern Ghana $^{*}$ & 228 & 36.1 \\
Mixed Tribes $^{* *}$ & 7 & 1.1 \\
Totals & 621 & 100
\end{tabular}

*Those from any of the tribes of Northern, Upper West and Upper East Region of Ghana; ${ }^{* *}$ Mixed tribe includes Nigeria, Burkina Faso and those with half/half from different tribes. 


\subsubsection{Food Vendors' Skills Transfer and Nationalization of Foods}

Women traditionally acquired their skills in food preparation from their mothers from generation to generation at home and in the vending business. Vendors transfer these skills to other people willing to learn apart from the regular process of from mother to daughter or children. About $70 \%$ of food vendors interviewed acquired this skill from their mothers. They had helped their mothers when they were young, doing smaller chores. Fifteen per cent learned through relatives and the remaining $17 \%$ through other vendors as they worked as assistants (Figure 1). Vendors maintained food ethnic identity through the transfer of the preparation methods. At the same time as the production and consumption of these foods spread throughout the country, these foods acquire their national identity through some modifications.

\section{Discussions}

Changes have occurred in the studied foods. Currently, Ghanaian dishes have gone through several processes with global influences. The ethnic based foods are accepted as nationwide foods and this can be attributed to national patriotism among Ghanaians expressed in patronizing local foods. Changes have occurred in ingredients used for the preparation of koko, waakye and kenkey to meet consumers' demands and to increase the profitability of vendors as foods move from ethnic into national spaces.

Despite the modifications however, foods maintained their local identity. The work of Huat (2001) on Chinese cuisines showed how foods were hybridized, changed but maintained unique identities within non-Chinese cultures. In the same way, the studied foods in Ghana maintain their identities as belonging to a specific ethnic group despite the modification processes that have occurred over time.

Although most of these cereals, legumes, and vegetables are improved varieties, either grown locally or imported into the country, people perceived them as local because they are cultivated or sourced from within the country. These improved local or imported ingredients do not affect the principles of the preparation of local cuisines.

Methods of cooking have changed with the additional ingredients and more efficient heating systems. Results show a gradual shift from firewood to charcoal and gas. However, the preparation of kenkey maintains the use of firewood among the studied vendors. This may be because of the nature of the preparation process, which involves precooking of dough and the final cooking or steaming (Amoa Awua et al., 2007). At the micro scale that vendors operate with at least one worker or on the average five workers, they may not be able to afford the use of charcoal pots, gas or even industrial cookers for kenkey preparation. They rather used charcoal pots and gas cookers for the preparation of sauces that accompany it.

Packaging has changed with plastics and polythene now used for safety and convenience. Although, this change with the use of plastics and polythene has a positive effect as a hygienic way of wrapping street-vended foods (Schweizer and Annoh, 1996; World Bank, 1995; Kumasi Metropolitan Assembly (KMA), 1995; Adarkwa and Edmundsen, 1993) it also has its negative effect on the environment with improper disposal. Again, while most consumers considered that the improved packaging of food rendered it safe for consumption, others were concerned about consequence of heat on polythene and their effect on food and health of consumers (Haleegoah et al., 2015).

In sum, these changes, whether slight or complete, indicate global influence on local dishes in one way or the other and the study confirms other findings that global and local food practices cannot be distinguished or separated; they are interrelated (Quaye et al., 2010; Ruivenkamp and Jongerden, 2005; Yeung, 1998; Eade, 1997).

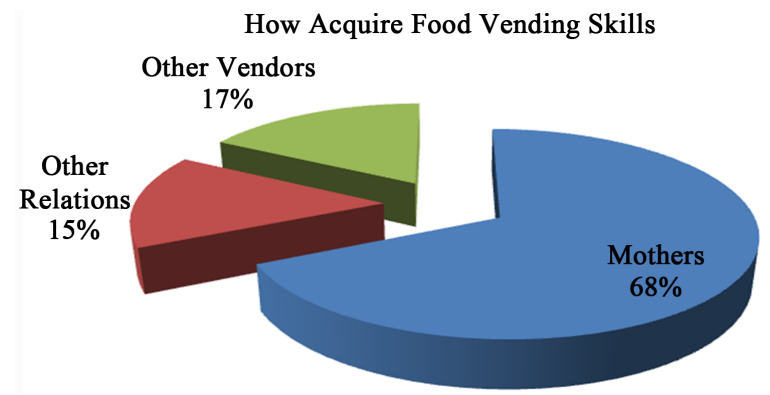

Figure 1. How vendors acquire their food vending skills. 


\subsection{Local Food Cultural-Ethnic and National Identities and Transformation}

Results show that the studied foods provided individual identity for people of some specific ethnic group and at the same time a collective one for all Ghanaians through its vending and consumption. This is in agreement with other studies that show that food consumption culture provided individual as well as collective identity for a group of people (Ohna et al., 2012; Palmer, 1998; Appadurai, 1988).

The process of making ethnic specific dishes available for the consumption of all Ghanaians reflects the simultaneous process of ethnic specialization and the development of crosscutting national cuisines (Appadurai, 1988). Results from this studied foods show that vendors play key role in this process. They make use of available resources, revalorize and transform it to meet demands of consumers. They also transmit the knowledge and skills of food vending to their children and other women and through these processes, foods of ethnic identities assume national identities.

The different versions of the same food available for people shows that food, as an entity though assumes some form of permanency changes with time. As foods interact with different people in their preparation and consumption, they change but maintain their identities. Again, within the realm of culinary experimentation, people have different ways of preparing similar foods maintaining the common principles of preparation creating diversity in culinary designs (Osseo-Asare, 2005). Osseo-Asare (2005) raised two issues when addressing food cultures. One is where culture holds on to its traditions and the other is the flexibility for transformation, experimentation and adaptation of food. People always explore available resources (local or global) to arrive at the preferred taste of culinary products to satisfy their needs and preferences. These food habits change with time and space since movement requires adaptation to a new environments.

\subsection{Reinventing Local}

Local origins and global influences are interrelated. Separating them becomes difficult as discourses on local foods suggest (Allen, 2010; Hinrichs, 2003). With changes, the question would be whether these dishes are local, global or "glocal” as Quaye et al. (2010) described it. The results from the study show that indeed, there are interactions between local and global expressed in some of the changes observed.

The processes of appropriation and substitution play an important role in local foods transformation. Appropriation is the gradual replacement of controllable biological processes from farming practices by external institutions, especially, industries. Substitution on the other hand is the gradual replacement of food source of agrarian origin by industrialized and manufactured products (Ruivenkamp, 2005). Changes observed in studied food reflect these processes. Some ingredients are replaced or substituted while others are added on.

Accompaniments such as sauces, soups, salads, the use of processed vegetables and fish as well as spices for waakye and kenkey are a clear indication of global influence on local foods. The packaging of local foods in plastic bags and Styrofoam carriers as take-away bags by consumers is also an example of national regulatory endeavors and global influences.

In sum, different people learn to prepare and consume the local dishes of some specific ethnic groups in urban areas. The cultural migration of people to different parts of the country, the narratives and memories of women food vendors move foods from ethnic to national identity sustaining local development and nation patriotism.

\section{Conclusion}

Food dynamism in the three studied foods is shown from their preparation to consumption in terms of ingredients used, cooking methods, packaging and serving practices. These changes or modifications show that Ghanaian foods do not stand on their own as indigenous but several factors mediated to re-invent them as local dishes. These are colonial encounters, which introduced some food crops into the country, current global encounters and cultural migration enhanced through food vendors and consumers.

Foods identified with some specific ethnic groups are at the same time identified as national foods, giving a national identity to such foods. What nurtures this national identity are the several actors and mediums (authors, national web sites, media, food vendor and consumers) who in one way or the other ensemble these ethnic foods into national ones.

\section{Recommendations}

The main cereals used for the preparation of these foods are locally grown and the paper recommends that poli- 
cies to sustain local agricultural production in the country should include the promotion of these local dishes to strengthen and sustain the local food system for national development.

There is the need for a specific street-vended cooked food policy that takes into account this changing nature of our local foods, which is often not realized due to permanency ascribed to food. Again, existing policies should be enforced to ensure that street-vended foods in general play their important role in ensuring urban food security. Given attention to food cultural transformation, will revalorize local resources to sustain local and national development.

\section{Acknowledgements}

We wish to acknowledge all actors' who cooperated with the researcher for the continually interactions with them as well as the observations of their activities. We also would like to thank Nuffic, The Netherlands Government for sponsoring the $\mathrm{PhD}$ work, which has resulted in this paper. We say thank you to all colleagues for their comments on this paper.

\section{References}

Adarkwa, K. K., \& Edmundsen, A. R. (1993). Urban Waste Management in Ghana, a Study of Eleven Urban Centers. Kumasi: University of Science and Technology.

Agbozo, C. (2007). Aromas from Ghana. An Introduction to Ghanaian Cuisine. Canada: DaySpring Publishers.

Allen, P. (2010). Realizing Justice in Local Food Systems. Cambridge Journal of Regions, Economy and Society, 3, $295-308$. http://dx.doi.org/10.1093/cjres/rsq015

Amoa Awua, W. K., Ngunjiri, P., Anlobe, J., Kpodo, K., Halm, M., Hayford, A. E., \& Jakobsen, M. (2007). The Effect of Applying GMP and HACCP to Traditional Food Processing at a Semi-Commercial Kenkey Production Plant in Ghana. Food Control, 18, 1449-1457. http://dx.doi.org/10.1016/j.foodcont.2006.10.009

Appadurai, A. (1988). How to Make a National Cuisine: Cookbooks in Contemporary India. Comparative Studies in Society and History, 30, 3-24. http://dx.doi.org/10.1017/S0010417500015024

Appadurai, A. (2008). How to Make a National Cuisine: Cookbooks in Contemporary India. In C. Counihan, \& P. Van Esterik (Eds.), Food and Culture (pp. 289-307). New York and London: Routledge Taylor and Francis Groups.

Atlin, G. N., Palacios, N., Babu, R., Das, B., Twumasi-Afriyie, S., Friesen, D. K., De Groote, H., Vivek, B., \& Pixley, K. V. (2011). Quality Protein Maize: Progress and Prospects. In J. Janick (Ed.), Plant Breeding Reviews (Vol. 34, pp. 83-130). Hoboken, NJ: John Wiley \& Sons. http://dx.doi.org/10.1002/9780470880579.ch3

Boahene, C. (2003). The Best of Our Foods. Accra: Afram Publications.

Coetzee, J. J. (1995). Cowpea: A Traditional Crop in Africa. Africa Crop Info 95 Leaflet. Pretoria: Vegetable and Ornamental Plant Institute and the Grain Crops Institute, Agricultural Research Council.

Cook, I., \& Philip, C. (1996). The World in a Plate: Culinary Culture, Displacement and Geographical Knowledge. Journal of Material Culture, 1, 131-154. http://dx.doi.org/10.1177/135918359600100201

Couderc, P. (1995). Les Plats qui ont fait la France. Paris: Editions Julliard.

Cusack, I. (2000). African Cuisines: Recipes for Nation Building? Journal of African Cultural Studies, 13, 207-225. http://dx.doi.org/10.1080/713674313

Eade, J. (1997). Introduction, Living the Global City: Globalization as a Social Process (pp. 1-19). London and New York: Routledge Taylor and Francis Groups. http://dx.doi.org/10.4324/9780203284155

Haleegoah, J., Guido, R., George, E., Godfred, F., \& Joost, J. (2015). Street-Vended Local Food Systems Actors Perceptions on Safety in Urban Ghana: The Case of Hausa Koko, Waakye and Ga Kenkey. Advances in Applied Sociology, 5, $134-145$. http://dx.doi.org/10.4236/aasoci.2015.54013

Hinrichs, C. (2003). The Practice and Politics of Food System Localization. Journal of Rural Studies, 19, 33-45. http://dx.doi.org/10.1016/S0743-0167(02)00040-2

http://www.ghananation.com/tourism/Local-Favorite-Dishes-you-must-definitely-try.asp.

http://www.touringghana.com/dining.asp\#top.

Huat, C. B., \& Ananda, R. (2001). Hybridity, Ethnicity and Food in Singapore. In D. Y. H. Wu, \& C. B. Tan (Eds.), Changing Chinese Foodways in Asia (pp. 161-197). Hong Kong: The Chinese University Press.

Johnson, D. T. (1970). The Cowpea in the African areas of Rhodesia. Rhodesia Agricultural Journal, 7, 61-64. 
Kudonoo, E. C. (2007). The Ghanaian Colour Cookbook—A Taste of Ghana. Accra: SEDCO.

Kumasi Metropolitan Assembly (KMA) (1995). Strategic Sanitation Plan for Kumasi 1996-2005. Kumasi: Kumasi Metropolitan Assembly.

Ohna, I., Kaarhus, R., \& Kinaba, J. (2012). No Meal without Ugali? Significance of Food and Consumption in a Tanzania Village. Culture, Agriculture, Food and Environment, 34, 3-14. http://dx.doi.org/10.1111/j.2153-9561.2012.01061.x

Osseo-Asare, F. (2005). Food Culture in Sub-Saharan Africa. London: Greenwood Press.

Osseo-Asare, F. (2008). http://www.betumiblog.blogspot.com/search?q=cookbooks.

Palmer, C. (1998). From Theory to Practice: Experiencing the Nation in Everyday Life. Journal of Material Culture, 3, 175199. http://dx.doi.org/10.1177/135918359800300203

Pilcher, J. M. (1996). Tamales or Timbales: Cuisine and the Formation of Mexican National Identity, 1821-1911. The Americas, 53, 193-216. http://dx.doi.org/10.2307/1007616

Quaye, W., Joost, J., George, E., \& Guido, R. (2010). Globalization vs. Localization: Global Food Challenges and Local Solutions. International Journal of Consumer Studies, 34, 357-366. http://dx.doi.org/10.1111/j.1470-6431.2010.00868.x

Ruivenkamp, G. (2005). Tailor-Made Biotechnologies: Between Bio-Power and Sub-Politics. Tailoring Biotechnologies, 1, 11-33.

Ruivenkamp, G., \& Joost, J. (2005). Critical Theory of Technology and Theoretical Critiques. Tailoring Biotechnologies, 1, 5-9.

Schweizer, F., \& Annoh, C. K. (1996). Privatization of Solid Waste Management in Ghana. Trialog, 48, 50-55.

Smart, J. (2003). Ethnic Entrepreneurship, Transmigration, and Social Integration: An Ethnographic Study of Chinese Restaurant Owners in Rural Western Canada. Urban Anthropology, 32, 311-342.

Summerfield, R. J., Huxley, P. A., \& Steel, W. (1974). Cowpea (Vigna unguiculata (L.) Walp.). Field Crop Abstracts, 27, 301-312.

Tindall, D. (1983). Vegetables in the Tropicals. London: Macmillan Education Ltd. http://dx.doi.org/10.1007/978-1-349-17223-8

World Bank (1995). Ghana, Growth, Private Sector, and Poverty Reduction, a Country Economic Memorandum. Washington DC: World Bank.

Yeung, H. (1998). Capital, State and Space: Contesting the Borderless World. Transactions of the Institute of British Geographers News Series, 23, 291-309. http://dx.doi.org/10.1111/j.0020-2754.1998.00291.x 